\title{
Evaluation of methods for typing coagulase-negative staphylococci
}

\author{
M. S. DRYDEN, H. G. TALSANIA, S. MARTIN $\dagger$, M. CUNNINGHAM*, J. F. RICHARDSON†, \\ B. COOKSON $\dagger$, R. R. MARPLES $\dagger$ and I. PHILLIPS
}

Department of Microbiology, St Thomas' Hospital, UMDS, London SE1 7EH, " Department of Microbial Diseases, Institute of Dermatology, UMDS, London SE1 7EH and † Division of Hospital Infection, Central Public Health Laboratory, 61 Colindale Avenue, London NW9 5HT

\begin{abstract}
Summary. One hundred and forty-two coagulase-negative staphylococci (CNS) isolated from dialysate effluent or skin of patients receiving continuous ambulatory peritoneal dialysis (CAPD) were typed by extended antibiogram (16 antibiotics) and biotype (26 reactions). These isolates were then typed by supplementary methods to determine the most suitable typing method for an epidemiological study of antibiotic resistance. These included phage typing, reverse phage typing, plasmid typing, whole-cell protein typing by SDS-PAGE with analysis by densitometry, and immunoblotting. The percentage of isolates typed successfully by the supplementary methods were: phage typing $20 \%$, reverse phage typing $0 \%$, plasmid typing $66 \%$, SDS-PAGE $100 \%$, immunoblotting $100 \%$. The discrimination of each method was: phage typing $20 \%$, plasmid typing $37 \%$, SDS-PAGE $69 \%$, immunoblotting $57 \%$. Reproducibility was $88 \%$ for phage typing and $97 \%$ for plasmid typing. The reproducibility of the whole-cell protein typing was $83 \%$ if the same extracts were used but only $43 \%$ when separate protein extracts were analysed on separate occasions. However, strain relatedness was highly reproducible. The determination of an antibiogram-biotype profile was not a sufficiently accurate typing method for an epidemiological study of antibiotic resistance. Whole-cell protein typing by SDS-PAGE or immunoblotting was technically demanding but was the most effective of the supplementary methods for detecting erroneous discrimination and false matching produced by antibiogram-biotype combinations.
\end{abstract}

\section{Introduction}

Infection with coagulase-negative staphylococci (CNS) is an increasing problem in hospital practice ${ }^{1}$ but no effective single typing method exists with which to investigate the epidemiology of these infections. In previous studies we reported that a combination of four methods was required to distinguish strains of CNS causing peritonitis in patients receiving continuous ambulatory peritoneal dialysis (CAPD). ${ }^{2}$ The scheme consisted of an extended antibiogram, biotype, phage type and plasmid profile and was successfully applied to an investigation of the epidemiology of CNS peritonitis in CAPD patients. ${ }^{3}$ The antibiogram was identified as the most discriminatory of these methods. However, in the investigation of the epidemiology of antibiotic resistance in strains of CNS isolated from CAPD patients it is impossible to rely on the antibiogram alone; unrelated strains may have the same resistance pattern and related strains may be dis-

Received 15 Sept. 1991 : accepted 5 Oct. 1991.

Correspondence should be sent to Dr M. Dryden, Department of Microbiology, Royal Hampshire County Hospital, Winchester, Hants SO22 5DG. tinguished falsely on the basis of differences in antibiograms. Both antibiotic resistance and plasmid carriage have been shown to be unstable in a single strain of Staphylococcus epidermidis, ${ }^{4}$ and in a study of a large number of strains by antibiogram-biotype, phage susceptibility, serotyping and plasmid profile, variability in all these characteristics was common amongst related strains. ${ }^{5}$

Using the antibiogram and biotype as the basis for the typing scheme, we aimed in addition to evaluate the following techniques: phage susceptibility typing, reverse phage typing, plasmid profile typing, wholecell protein and polypeptide analysis by SDS-PAGE and Western immunoblotting. SDS-PAGE has been used as a taxonomic tool for staphylococci ${ }^{6,7}$ and in epidemiological investigations. ${ }^{8,9}$ Immunoblotting has been applied in the assessment of the relevance of blood-culture isolates of $\mathrm{CNS}^{10}$ and phage typing and plasmid profiles have been widely used. Previous studies of SDS-PAGE in the investigation of CNS have been hampered by a lack of an objective method of analysis of the protein bands, but in this study we used optical scanning of SDS-PAGE gels by densitometry, a technique successfully applied to agro- 
bacteria and Zymomonas, ${ }^{11}$ methicillin-resistant $S$. aureus, ${ }^{12}$ and yeasts. ${ }^{13}$

Initially, a collection of clinical CNS isolates which could be distinguished by antibiogram plus biotype was examined and each of the supplementary methods was used to determine whether false discrimination by the basic methods could be detected. Further isolates known to be epidemiologically related or unrelated to the study strains were also examined to test the suitability of the supplementary methods for an epidemiological study.

\section{Materials and methods}

\section{Bacterial isolates}

Initially, 35 CNS strains isolated from the dialysate effluent of CAPD patients with peritonitis and which could be distinguished by a combination of antibiogram and biotype were used to test the efficacy of the supplementary typing methods. Subsequently, a further 107 isolates were chosen on the basis of either their suspected relatedness to one of the original 35 strains or their obvious unrelatedness; 100 of the 107 isolates were from skin or dialysate effluent from CAPD patients. Of these, isolates defined as "related" included those collected at widely-spaced time intervals from the same patient that were indistinguishable by antibiogram plus biotype from a strain in the original collection of 35 strains. "Unrelated" isolates were isolated from patients not represented in the original collection of 35 strains. Four of the 107 isolates were skin strains obtained from the staphylococcal collection at the Central Public Health Laboratory, Colindale Avenue, London, and three were significant blood-culture isolates from patients at $\mathrm{St}$ Thomas' Hospital, London, who had no connection with the Renal Unit.

"Related" isolates were paired with their associated strain from the original collection, and "unrelated" isolates were randomly allocated to one of the original strains. Pairs of isolates were typed by the supplementary methods. Thus each of the 107 isolates, related or unrelated to a strain in the original collection, could also be described as distinguishable or indistinguishable from its associated strain by each supplementary method. The positive predictive value, defined as the ability of a method to find related strains indistinguishable, or the negative predictive value, the ability of a method to differentiate unrelated strains, was calculated from four-fold tables.

All isolates were stored in Nutrient Broth (Oxoid) with glycerol $15 \%$ at $-70^{\circ} \mathrm{C}^{14}$ and recovered for this study by subculture on Columbia Agar Base (Oxoid, CM331) with horse blood (102-00001H, Bio-Cult Diagnostics Ltd, Paisley) $7 \%$ incubated at $37^{\circ} \mathrm{C}$ for $18 \mathrm{~h}$.

Plating procedure. One colony was transferred to $3 \mathrm{ml}$ of sterile water. A cotton swab was used to transfer part of this suspension to a quarter of a blood agar plate, for methicillin sensitivity testing, and to two plates of DST Medium (Oxoid, CM261) with horse blood (6\%) lysed by white saponin (44092, BDH Chemicals Ltd, Poole). The remainder of the suspension was used to determine the biotype. Colonies from the original purity plate were inoculated into $40 \mathrm{ml}$ of nutrient broth in preparation for wholecell protein analysis and immunoblotting.

\section{Typing methods}

Each typing method was evaluated for typability (i.e., proportion of strains that could be typed), discrimination and reproducibility.

Antibiogram and biotyping. Extended antibiotic susceptibility testing with 16 agents was performed by a disk diffusion method on lysed blood agar. ${ }^{15}$ The following antibiotic disks were applied by an Oxoid disk dispenser: penicillin $5 \mathrm{IU}$, erythromycin $5 \mu \mathrm{g}$, tetracycline $50 \mu \mathrm{g}$, gentamicin $10 \mu \mathrm{g}$, fusidic acid $10 \mu \mathrm{g}$, clindamycin $2 \mu \mathrm{g}$, rifampicin $2 \mu \mathrm{g}$, neomycin $30 \mu \mathrm{g}$, vancomycin $30 \mu \mathrm{g}$, chloramphenicol $10 \mu \mathrm{g}$, mupirocin $5 \mu \mathrm{g}$, streptomycin $25 \mu \mathrm{g}$, novobiocin $5 \mu \mathrm{g}$, trimethoprim $2 \cdot 5 \mu \mathrm{g}$, ciprofloxacin $1 \mu \mathrm{g}$, methicillin $10 \mu \mathrm{g}$. The plates were read after incubation for $24 \mathrm{~h}$ at $37^{\circ} \mathrm{C}$; methicillin plates were incubated at $30^{\circ} \mathrm{C}$. Discrimination between strains was based on a single antibiotic resistance difference.

Biotyping was performed with the ATB 32 Staph System (API products Ltd, Basingstoke, Hampshire). This method gave a nine-figure profile; discrimination between strains was based on a single biochemical difference.

Phage typing was performed at the Staphylococcus Reference Unit, Central Public Health Laboratory, Colindale Avenue, London, according to the scheme developed by Dean et al. ${ }^{16}$ and interpreted as described previously. ${ }^{17}$

Reverse phage typing. The extraction of free phage from the 35 strains by induction with mitomycin $\mathrm{C}$ was attempted by the method of Richardson et al. ${ }^{18}$ Broth cultures of the staphylococcal strains were treated with mitomycin C. After incubation and centrifugation, the supernate was spotted on propagating strains for the CNS phages and on to the 35 test strains themselves to detect any released phages.

Plasmid typing. Plasmids were extracted and separated by agarose gel electrophoresis. ${ }^{2}$ Plasmid preparations were interpreted by the method of Degener $e t$ $a l .{ }^{19}$ Isolates were considered to be indistinguishable if they possessed plasmids of identical mobility.

Whole-cell protein typing. SDS-PAGE was performed by a modification of the method of Clink and Pennington. ${ }^{6}$ Meticulous technical standardisation was essential for the success and reproducibility of this technique. Samples were prepared by broth culture, centrifugation and sonication $(20 \mathrm{kHz}, 47 \mathrm{~W})$ of a suspension in sterile distilled water for $5 \mathrm{~min}$ (W-385, Heat Systems-Ultrasonics Inc., Farmingdale, NY, USA). Electrophoresis was performed on a polyacrylamide $10 \%$ gel in a discontinuous buffer system at 
$10^{\circ} \mathrm{C}$ and gels were stained with Page Blue 83 (BDH $0.1 \%$ ). Mol. wt marker polypeptides (Pharmacia, Uppsala, Sweden) and protein preparation from a control strain of $S$. aureus were included in each gel.

Immunoblotting was performed with hyperimmune rabbit serum. Two rabbits were immunised with a strain of $S$. epidermidis isolated from a patient with CAPD peritonitis, in a 5-week protocol..$^{20}$ The strain was grown on blood agar, washed and suspended in buffered saline to a concentration of $10^{8}-10^{9} \mathrm{cfu} / \mathrm{ml}$. The rabbits were bled before immunisation and then immunised on day 1 subcutaneously, day 6 intramuscularly with Freund's adjuvant, and on days 12, $14,16,18,20,22$ and 29 via the marginal ear vein. Rabbits were test bled before being finally bled. Protein was transferred to nitrocellulose membranes (0.45 $\mu \mathrm{m}$; Schleicher and Schuell, Dassel, Germany) with a $100 \mathrm{~mA}$ current for $15 \mathrm{~h}$.

SDS-PAGE gels were scanned by a densitometer (Chromoscan 3, Joyce Loebl, Marquisway, Tyne and
Wear) by a modification of the method of Jackman. ${ }^{21}$ Each track was scanned at a rate of $30 \mathrm{~mm} / \mathrm{s}$, with $A_{550}$ values being measured at $0 \cdot 2-\mathrm{mm}$ intervals. The output voltage from the densitometer was converted into a series of integer values and this information was transmitted to a Sage IV microcomputer (TDI, 47 Alma Vale Rd., Bristol). Each trace was corrected for gel-to-gel variation in a calibration pattern run for every gel based on the mol. wt standard. Each was compared with every other trace by the correlation coefficient to form a similarity matrix; this was then clustered by the unweighted pair-group method of averages (UPGMA). ${ }^{22}$ Strains were regarded as indistinguishable if the percentage relatedness was equal to or greater than that for the control strains of $S$. aureus.

Immunoblots were examined visually. A difference in the position or intensity of at least three antigenic bands was the criterion used to distinguish strains. ${ }^{10}$

Table I. Characteristics of 35 strains of CNS isolated from peritoneal dialysate

\begin{tabular}{|c|c|c|c|c|c|c|c|}
\hline $\begin{array}{c}\text { Strain } \\
\text { no. }\end{array}$ & $\begin{array}{c}\text { Antibiogram* } \\
\text { PETGFDRYVCUSNOXM }\end{array}$ & Biotype $\dagger$ & Phage type $\dagger$ & Plasmid profile $\dagger$ & SDS $†$ & Blot $\dagger$ & Species \\
\hline 1 & PETG---Y---S-OX- & 1 & 0 & 10 & 1 & 1 & S. haemolyticus \\
\hline 2 & PETG -- $\mathrm{Y}_{---S}----$ & 2 & 0 & 0 & 1 & 1 & S. haemolyticus \\
\hline 3 & PETG----C-C-OX- & 3 & 1 & 1 & 14 & 2 & S. epidermidis \\
\hline 4 & PETG $-\ldots \mathrm{S}--\mathrm{X}-$ & 1 & 0 & 10 & 1 & $i$ & S. haemolyticus \\
\hline 5 & PETG-_-_--_S--_- & 2 & 0 & 10 & 1 & 1 & S. haemolyticus \\
\hline 6 & PET - $-C-C-O X-$ & 3 & 1 & 1 & 14 & 2 & S. epidermidis \\
\hline 7 & PE-G-D-Y-C-OXM & 3 & 0 & 6 & 15 & 3 & S. epidermidis \\
\hline 8 & $\mathrm{PE}-\mathrm{G}--$ & 2 & 0 & 0 & 3 & 1 & S. haemolyticus \\
\hline 9 & $\mathrm{PE}-\mathrm{G}-------\mathrm{S}--\mathrm{X}-$ & 2 & 0 & 10 & 3 & 1 & S. haemolyticus \\
\hline 10 & $\mathrm{PE}-\mathbf{G}---------\mathrm{O}--$ & 3 & 0 & 2 & 16 & 2 & S. epidermidis \\
\hline 11 & $\mathrm{PE}--\mathrm{F}_{---}--------$ & 3 & 2 & 2 & 17 & 5 & S. epidermidis \\
\hline 12 & $\mathrm{PE}----\mathrm{C}--\mathrm{OX}-$ & 3 & 0 & 1 & 14 & 2 & S. epidermidis \\
\hline 13 & $\mathbf{P E}------C---\mathrm{O}-\mathbf{M}$ & 4 & 0 & 1 & 18 & 6 & S. epidermidis \\
\hline 14 & $\mathrm{PE}-{ }_{-}----\mathrm{S}-\mathrm{O}-\mathrm{M}$ & 5 & 0 & 11 & 4 & 1 & S. haemolyticus \\
\hline 15 & $\mathrm{P}-\mathrm{T}-\mathrm{F}-\mathrm{-}-\mathrm{N}-\mathrm{M}$ & 6 & 0 & 0 & 11 & 7 & S. cohnii \\
\hline 16 & $\mathbf{P}-\mathbf{T}-\mathrm{F}-$ & 7 & 0 & 0 & 2 & 1 & S. haemolyticus \\
\hline 17 & $\mathrm{P}-\mathrm{T}-----------$ & 3 & 0 & 3 & 19 & 8 & S. epidermidis \\
\hline 18 & $\mathrm{P}--\mathrm{G}---\mathrm{Y}---\mathrm{S}----$ & 8 & 0 & 0 & 5 & 9 & Staphylococcus sp. \\
\hline 19 & $\mathbf{P}-\mathbf{G}-\mathrm{Y}--\mathrm{OXM}$ & 4 & 0 & 4 & 21 & 10 & S. epidermidis \\
\hline 20 & $\mathbf{P}-\mathbf{G}_{---} \mathbf{Y}_{--}$ & 3 & 0 & 5 & 21 & 10 & S. epidermidis \\
\hline 21 & $\mathrm{P}---\mathrm{F}---$ & 3 & 0 & 0 & 21 & 12 & S. epidermidis \\
\hline 22 & 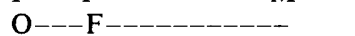 & 4 & 0 & 7 & 23 & 12 & S. epidermidis \\
\hline 23 & $\mathrm{P}$ & 4 & 3 & 0 & 24 & 14 & S. epidermidis \\
\hline 24 & $\mathbf{P}_{--}-\ldots$ & 3 & 4 & 8 & 22 & 15 & S. epidermidis \\
\hline 25 & $-\mathrm{ET}----$ & 4 & 0 & 2 & 22 & 16 & S. epidermidis \\
\hline 26 & $-\mathrm{E}-\cdots$ & 9 & 0 & 0 & 12 & 7 & S. cohnii \\
\hline 27 & $-\mathbf{E}-----------\mathrm{O}$ & 16 & 0 & 0 & 6 & 13 & S. haemolyticus \\
\hline 28 & -- T-- - & 4 & 0 & 9 & 20 & 4 & S. epidermidis \\
\hline 29 & --_-_-------_--- & 2 & 0 & 12 & 2 & 1 & S. haemolyticus \\
\hline 30 & --_-_-_-_-_-_-_-_-_- & 10 & 0 & 0 & 8 & 17 & S. hominis \\
\hline 31 & --_--_-_-_-_--_-_-_ & 11 & 0 & 0 & 7 & 18 & S. simulans \\
\hline 32 & - - - & 12 & 0 & 0 & 13 & 19 & S. capitis \\
\hline 33 & -------- & 13 & 0 & 0 & 9 & 20 & Micrococcus sp. \\
\hline 34 & - & 14 & 5 & 0 & 10 & 15 & S. epidermidis \\
\hline 35 & ------- & 15 & 0 & 0 & 9 & 20 & Micrococcus sp. \\
\hline
\end{tabular}

* Capital letters in the antibiogram refer to resistance to the following antibiotics: $\mathrm{P}$, penicillin; E, erythromycin; T, tetracycline; G, gentamicin; F, fusidic acid; D, clindamycin; R, rifampicin; Y, neomycin; V, vancomycin; C, chloramphenicol; U, mupirocin; S, streptomycin; N, novobiocin ; O, trimethoprim; X, ciproflaxacin ; M, methicillin; - = sensitive.

$\dagger$ Numbers refer to distinct profiles for biotyping (ATB32 Staph), phage typing, plasmid typing, SDS-PAGE and immunoblotting; $O=$ not typable. 


\section{Results}

\section{Antibiotic susceptibility and biotype}

The 35 strains tested were selected on the basis of being able to be distinguished by antibiogram plus biotype (table I); 29 distinct and reproducible susceptibility patterns and 16 distinct biotype profiles were demonstrated. Biotype reproducibility was $86 \%$ accurate; five strains differed by a single biochemical reaction, usually a sugar fermentation, when the test was repeated. Seventeen strains were identified as $S$. epidermidis, represented by four profiles, 10 strains as $S$. haemolyticus with four profiles, two strains as $S$. cohnii with different profiles, single strains as $S$. hominis, S. simulans, S. capitis, an unidentified CNS and two strains of micrococci.

\section{Phage typing}

Only seven strains ( $20 \%$ ), all S. epidermidis, were susceptible to the set of phages, and two strains (nos. 3 and 6, table I) showed identical phage patterns. If the large number of untypable strains was included as one group this method had a discriminatory power of $20 \%$; it had a reproducibility of $88 \%$. Four strains demonstrated different phage susceptibility patterns on re-testing; two showed extra reactions, one major and one minor difference; one strain previously not typable was susceptible and one previously susceptible strain was not typable on re-testing.

\section{Reverse phage typing}

It was not possible to demonstrate extraction of free phages from any of the 35 strains after induction with mitomycin $\mathrm{C}$.
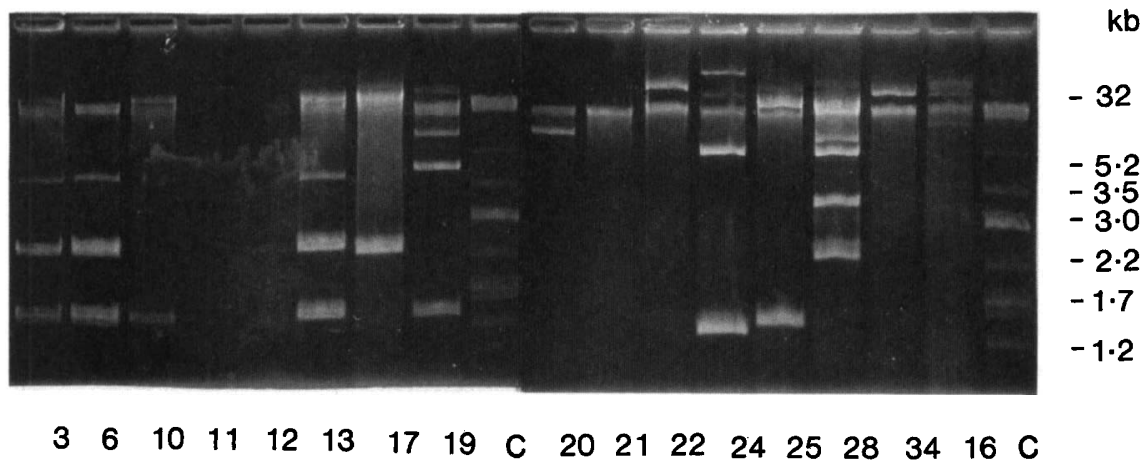

\section{Strain nos.}

Fig. 1. Plasmid profiles for strains of S. epidermidis. Track numbers refer to the strain reference numbers in table I; C, control Escherichia coli V517.

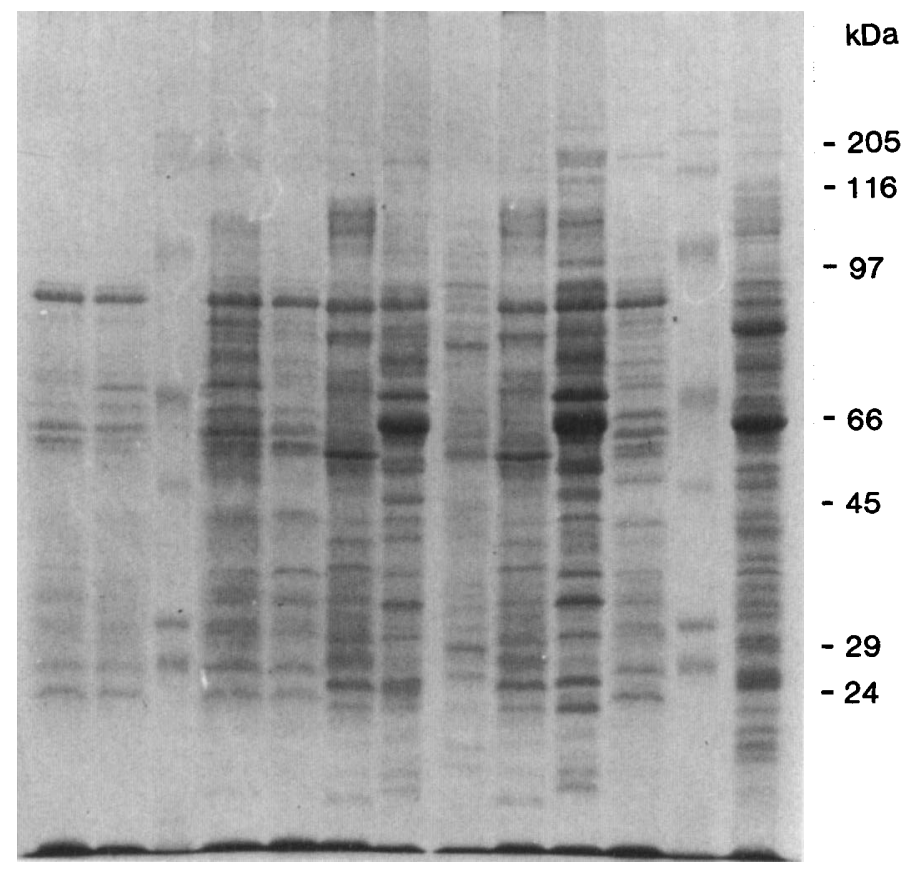

1011 MW $12 \quad 13$ os $14 \quad 15$ os 1617 MW 18

Fig. 2. SDS-PAGE of nine of the 35 original strains. Track numbers refer to the strain reference numbers in table I; MW, mol. wt marker; os, Oxford $S$. aureus control. 


\section{Plasmid typing}

Plasmid profiles were obtained with $23(66 \%)$ of the 35 strains. Most of those identified as $S$. epidermidis and $S$. haemolyticus contained plasmids but it was not possible to demonstrate the presence of plasmids in the other species. There were 13 distinct profiles, corresponding to a discrimination of $37 \%$. Plasmid profiles for strains of $S$. epidermidis are illustrated in fig. 1. Each distinguishable plasmid profile was given a number from 0 to $12 ; 0$ denoted an absence of demonstrable plasmids (table I).

\section{Whole-cell protein typing}

$S D S-P A G E$. All strains were typable by SDS-PAGE with large numbers $(>30)$ of bands visible (fig. 2). Visual inspection of the gels revealed typical band patterns for individual species (fig. 3a). Within species, minor differences in band patterns were observed and these differences were measured by densitometry (fig. 3b). Mol. wt markers allowed gels to be corrected for slight differences in the length of the tracks and control Oxford $S$. aureus tracks on each gel showed $\geqslant 90 \%$ relatedness. Any test strains that showed this degree of similarity were regarded as indistinguishable.

In gel analysis, 24 distinct protein band patterns were recognised, corresponding to a discrimination of $69 \%$. Reproducibility was $100 \%$ if the same extraction preparations were run on different gels in the same electrophoretic tank. The same extracts run in different electrophoretic tanks gave a reproducibility of $83 \%$. However, reproducibility was lower if separate protein extractions were run on different gels on separate occasions. This was performed for all 35 strains, and on comparison by densitometry with the original gels, only 15 pairs of strains showed $\geqslant 90 \%$ similarity, giving a $43 \%$ reproducibility for separate extractions. However, the relationships between strains was highly reproducible.

Fig. 4 is a dendrogram illustrating strain relatedness. The technique identified isolates to species level accurately. In the dendrogram, strains $1,2,4,5,16,29$, 14,8 and 9 are all S. haemolyticus. Strains 1, 2, 5 and 4 are indistinguishable, as are strains 8 and 9, demonstrating similar results to those obtained with the plasmid profile. Those isolates identified as S. epidermidis are clustered on the right of the dendrogram (strains 3-23). Strains 3, 6 and 12 were indistinguishable, confirming the result of the plasmid profile and phage typing. The other CNS species are clustered in the centre of the dendrogram. These include $S$. simulans (strain 31), S. hominis (strain 30), S. capitis (strain 32), S. cohnii (strains 15 and 26), an unidentified staphylococcus (strain 18), and Micrococcus spp. (strains 33 and 35).

Immunoblotting, like SDS-PAGE, gave distinct species patterns with minor band variation within species. Antigenic bands in immunoblots were less numerous than the protein bands of SDS-PAGE and
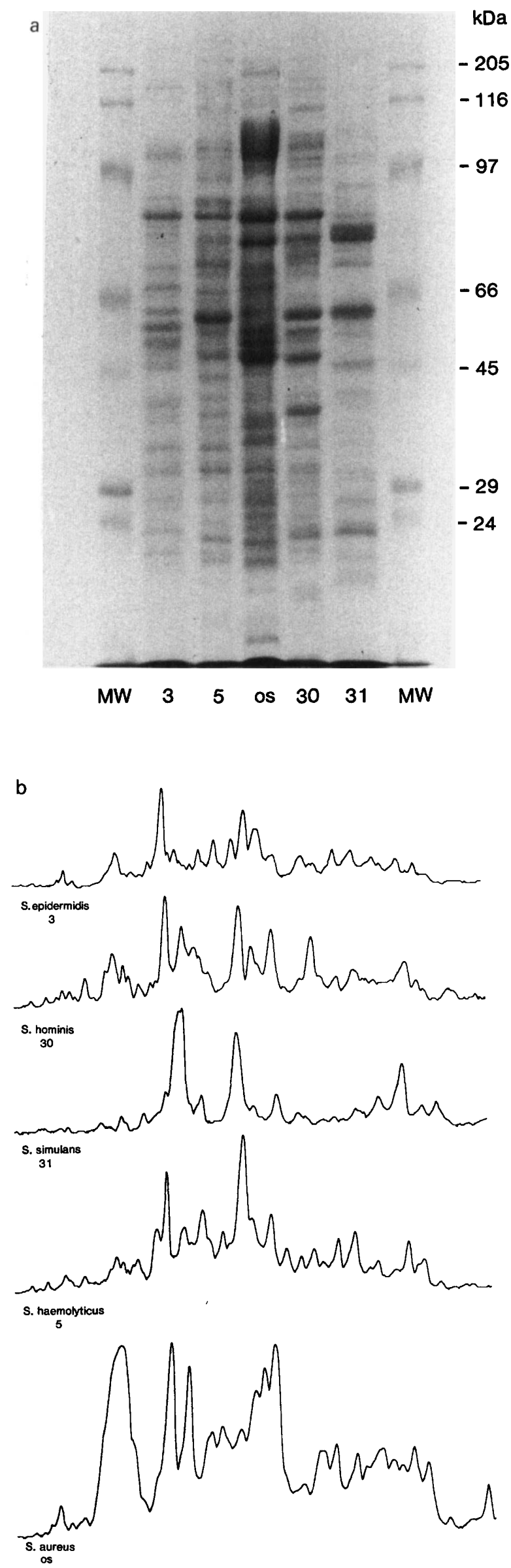

Fig. 3. (a) SDS-PAGE gel showing variation in protein band patterns between staphylococcal species and the densitometric traces (b); MW, mol. wt marker. 
Strain nos.

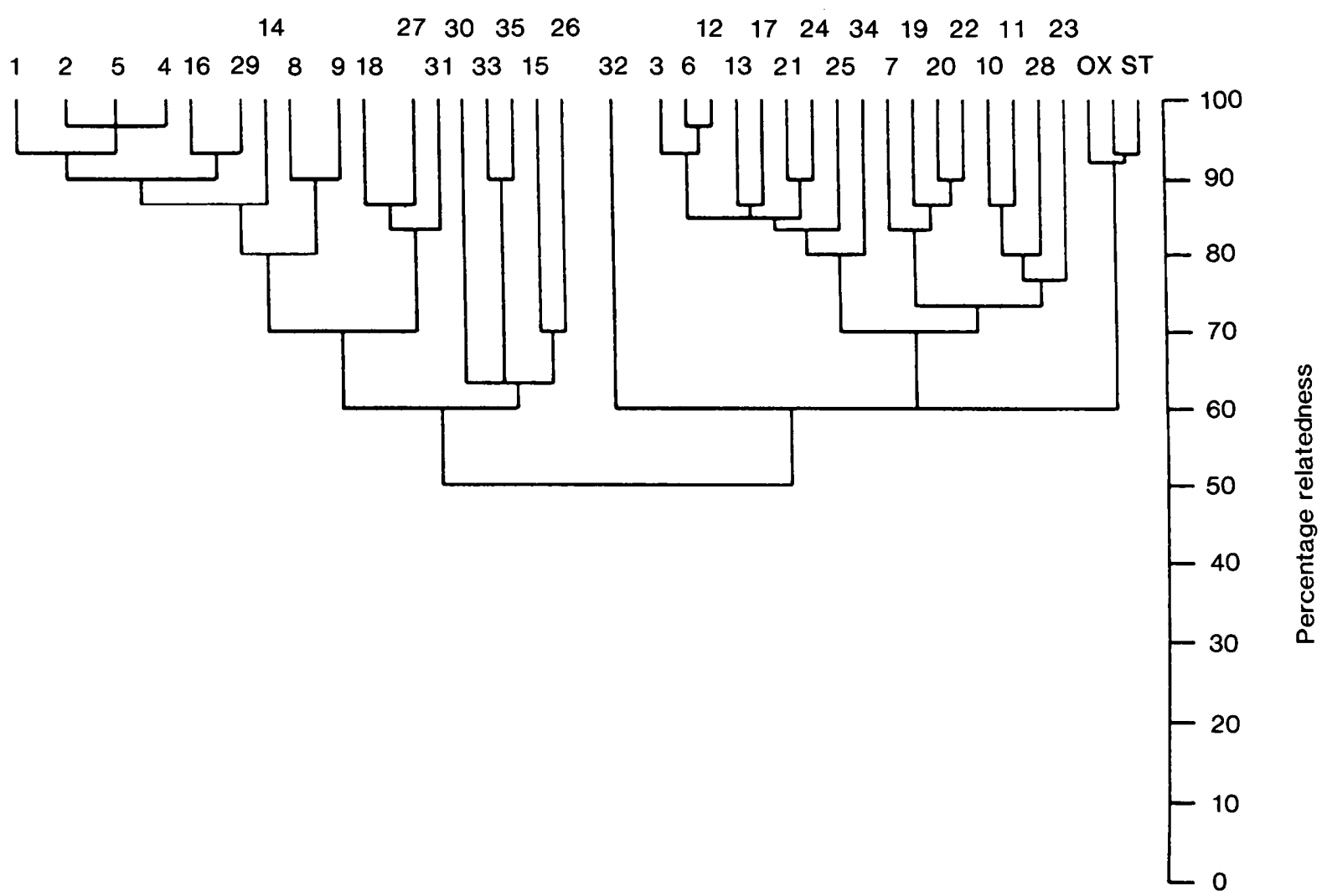

Fig. 4. Dendrogram illustrating the relatedness (\%) between protein band patterns of the 35 strains in table I; OX ST, Oxford $S$. aureus controls.

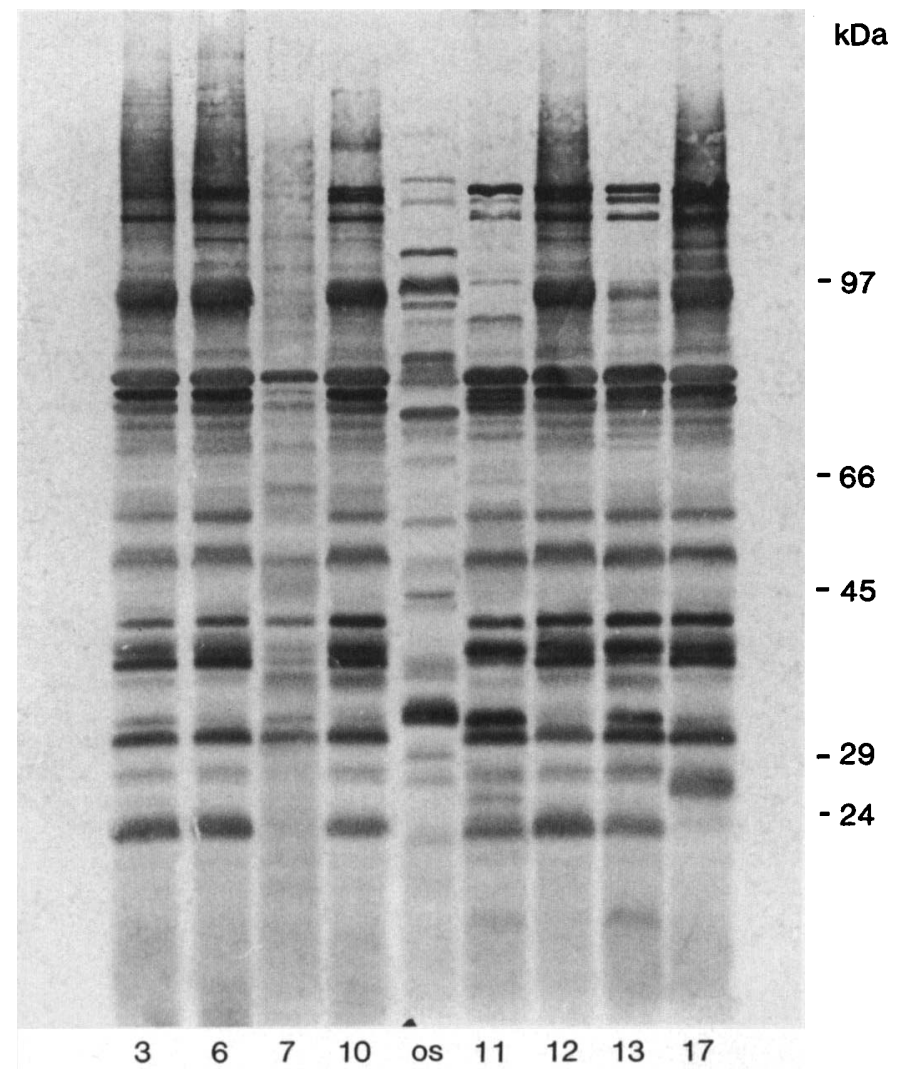

Fig. 5. Immunoblot of whole-cell protein of eight of the 35 original strains of $S$. epidermis. The track numbers refer to the strain reference numbers in table I; os, Oxford $S$. aureus control. 


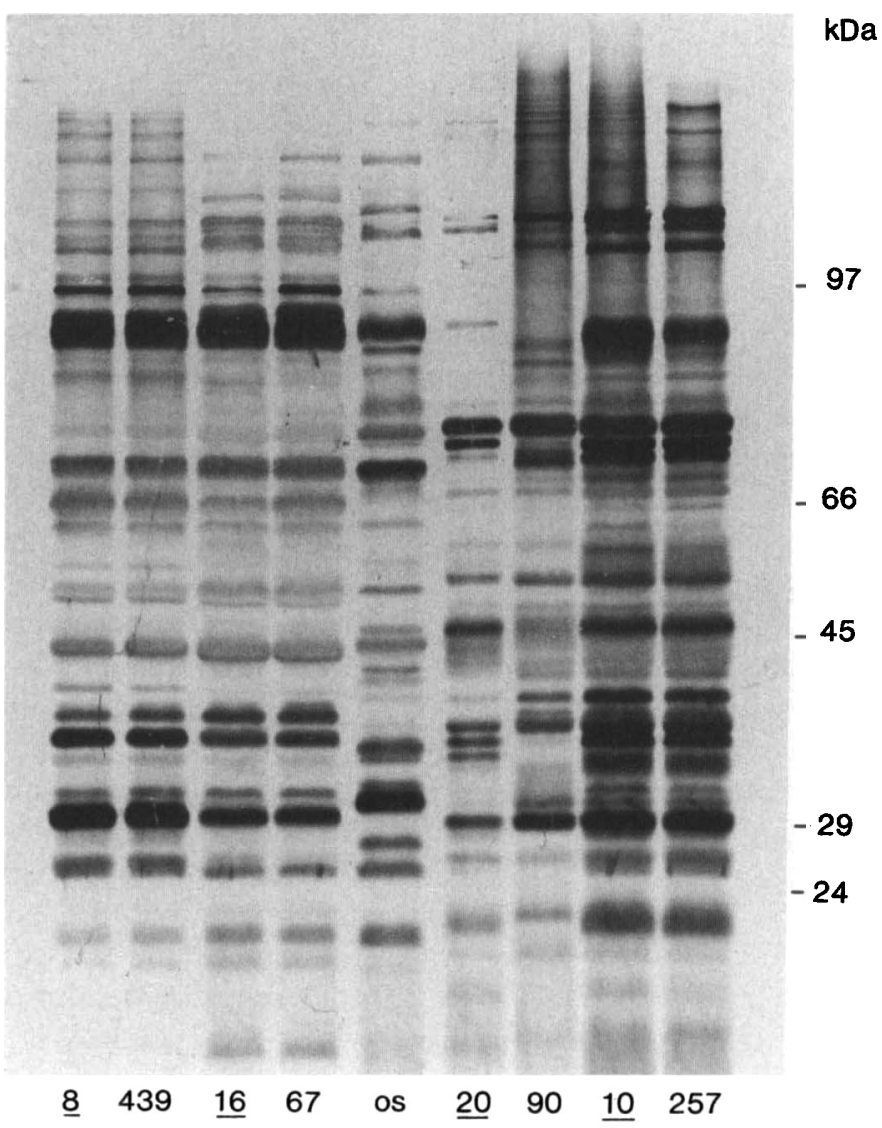

Fig. 6. Immunoblot of pairs of "related" isolates from amongst the 107 additional isolates. The numbers are the strain reference numbers, and those underlined are in the 35 original strains, in table I. Pairs 8 and 439, 16 and 67, 10 and 257 are indistinguishable. Pair 20 and 90 can be distinguished.

were, therefore, easier to read visually. Twenty distinct band patterns were recognised, representing a discriminatory power of $57 \%$. Fig. 5 illustrates an immunoblot of eight $S$. epidermidis strains. Strains 3, 6 , and 12 were indistinguishable. The technique was highly reproducible if the same protein extract preparations were run in the same or different electrophoretic tanks, providing that the same hyperimmune serum was used. Separate extracts run on different gels gave a reproducibility of $88 \%$. All but one of the $S$. haemolyticus strains were indistinguishable.

\section{Evaluation of supplementary techniques}

All strains were typed by SDS-PAGE and immunoblotting. Typability was $66 \%$ for plasmid profile but only $20 \%$ for phage typing. The supplementary techniques revealed false discrimination by antibiogram plus biotype of three strains of $S$. epidermidis. Strain 3 differed from strain 6 in its resistance to one antibiotic and strain 12 differed from strain 3 by two antibiotic results and from strain 6 by one. The biotype, plasmid profile, and protein analysis by SDSPAGE and immunoblotting of these strains were identical. Strains 3 and 6 were susceptible to phages $456,471 \mathrm{~A}$ and 459 , but strain 12 was not susceptible to any of the phages tested. Strains 6 and 12 were isolated from the same patient at an interval of 3 months, whereas strain 3 was isolated from a different patient with a strong epidemiological link to the first patient.

Many of the strains of $S$. haemolyticus were indistinguishable or closely related. The indistinguishable strains had very similar antibiograms and biotypes, and none was susceptible to the test phages.

Table II. Results of typing 107 CNS by supplementary methods with predictive values for each method

\begin{tabular}{ll|rccc}
\hline \multicolumn{1}{c|}{ Method } & \multicolumn{1}{c|}{ Result } & Related & Unrelated & PPV (\%) & NPV (\%) \\
\hline Plasmid analysis & Indistinguishable & 39 & 23 & 87 & 63 \\
\cline { 2 - 5 } SDS-PAGE & Distinguishable & 6 & 39 & & \multirow{2}{*}{ Indistinguishable } \\
\multirow{2}{*}{ Immunoblotting } & Distinguishable & 2 & 21 & 96 & 66 \\
& Indistinguishable & 44 & 26 & 98 & 58 \\
& Distinguishable & 1 & 36 & 98 & \\
\hline
\end{tabular}

PPV, Positive predictive value; NPV, negative predictive value. 
Strains 1, 4, 5 and 9 contained identical plasmids. Strains 1, 2, 4 and 5 were indistinguishable by SDSPAGE.

\section{Typing of the 107 additional isolates}

Forty-five isolates were epidemiologically related to strains in the original collection of $35 ; 62$ isolates were unrelated. All isolates were typed by SDS-PAGE and immunoblotting and $64(60 \%)$ by plasmid analysis. Fig. 6 shows an immunoblot of pairs of related organisms. Pairs 8 and 439, 16 and 67, 10 and 257 are indistinguishable. Pair 20 and 90, despite being indistinguishable by antibiogram plus biotype, are clearly distinguished by immunoblot. Table II lists the results for plasmid profile, SDS-PAGE and immunoblotting. The positive predictive value for strain relatedness was highest for SDS-PAGE $(96 \%)$ and immunoblotting $(97 \%)$, although the negative predictive values were not so high.

\section{Discussion}

The lack of an effective single typing method for CNS makes the investigation of the epidemiology of infection with these organisms laborious. Antibiogram and biotype are simple to perform and, whereas both methods have been shown to be discriminatory and reproducible, ${ }^{2}$ small differences between strains in resistance pattern or biotype may not be significant,,$^{4,5}$ and the antibiogram has a poor reputation as an epidemiological tool ${ }^{32}$ A further typing method is required to supplement these simple techniques. In this study, five supplementary techniques were examined: phage typing, reverse phage typing, plasmid typing, and whole-cell protein typing by SDS-PAGE and immunoblotting. SDS-PAGE analysis of CNS has been employed as a taxonomic tool ${ }^{6}$ and in epidemiological typing with ${ }^{35} \mathrm{~S}$-methionine-labelled bacteria ${ }^{9}$ and without radioactive labelling. ${ }^{8}$ Immunoblotting has been successful in demonstrating the relatedness of multiple blood-culture isolates. ${ }^{10}$

Initially, 35 strains of CNS isolated from dialysis effluent in CAPD patients with peritonitis were chosen because it was possible to distinguish them on the basis of antibiogram and biotype. The strains were typed by the supplementary methods to test for erroneous discrimination by the simple methods. Phage typing did not help. The technique had very poor typability and low discrimination with this collection of strains and has been reported to be inadequate in other studies. ${ }^{5}$ Reverse phage typing provided no information. Experimental phage sets, successfully extracted from strains of methicillin-resistant $S$. aureus by mitomycin $\mathrm{C}$ induction, have been used to identify epidemic strains ${ }^{18}$ and reverse phage typing has been successfully applied to CNS although the typability was poor. ${ }^{24}$

Typing by plasmid profile was more discriminatory, although $40 \%$ of this collection of strains could not be typed by this method. Plasmid-profile analysis suggested an erroneous discrimination on the basis of antibiogram and biotype between some strains of $S$. epidermidis and $S$. haemolyticus.

Whole-cell protein typing by SDS-PAGE and immunoblotting were the only supplementary methods by which all strains could be typed. Both methods are technically demanding and meticulous attention to standardise each step is necessary to ensure reproducibility, which was excellent if the same extracts of strains were run in the same electrophoretic tank, even if they were on different gels. It was less satisfactory if separate extracts were run on different gels on separate occasions. The automated measurement of band position and intensity was objective. Slight discrepancies between identical strains could be explained by minor differences in growth conditions, time and speed of centrifugation and conditions of electrophoresis. ${ }^{11}$ Most importantly, however, the relationship between strains was highly reproducible. If two strains were indistinguishable on one run, this relationship was maintained on subsequent runs if there were minor differences in band profile.

SDS-PAGE gave a large number of protein bands, and while these could be analysed visually, a more objective comparison was obtained with a computerised optical scanner. The high resolution of the gels and the facility of the computer program to correct track length between gels by aligning mol. wt standards permitted a direct comparison of tracks on different gels. The technique accurately identified and clustered CNS species and it was possible to demonstrate that band variation was significant and provided adequate information to distinguish strains. The computerised analysis of tracks of the 35 original strains gave results that agreed with phage typing and with plasmid profiles and showed that minor differences in antibiogram were not significant.

The strains of $S$. haemolyticus in the original collection showed $\geqslant 85 \%$ relatedness on the basis of protein analysis. We recognised that this collection was derived from a narrow clinical source and that the strains may not be representative of the species as a whole. Isolates of $S$. haemolyticus from other sources were collected and compared with the collection strains. Greater variability was found between these strains and the collection strains.

In the second part of the study 107 additional isolates were compared with strains from the original collection. SDS-PAGE and immunoblotting were the two supplementary techniques that gave the greatest typability and discrimination. This study is novel in its use of predictive values as a measurement of technique efficacy. Both techniques were highly successful in matching related strains and both achieved high positive predictive values; although low, the negative predictive values for all the supplementary techniques were similar. Immunoblotting produced fewer bands, enabling easy visual comparison of the tracks. 
It is intended to use whole-cell protein typing (both SDS-PAGE and immunoblotting) as a supplementary method in the investigation of the epidemiology of antibiotic resistance amongst CNS colonising and infecting CAPD patients. Many other techniques have been used to investigate isolates of $S$. aureus, such as peptidoglycan fingerprinting, ${ }^{25}$ immunoblotting of exported proteins and restriction enzyme fragmentation patterns ${ }^{26}$ penicillin-binding protein analysis ${ }^{27}$ and ribotyping. ${ }^{28}$ Further work is required to assess the suitability of these techniques for CNS. Most recently the typing of CNS by pyrolysis mass spectrometry has shown promise. ${ }^{29}$

\section{References}

1. Eykyn SJ. Staphylococcal sepsis: the changing pattern of disease and therapy. Lancet 1988; 1: 100-104.

2. Ludlam HA, Noble WC, Marples RR, Phillips I. The evaluation of a typing scheme for coagulase-negative staphylococci suitable for epidemiological studies. J Med Microbiol 1989; 30: $161-165$

3. Ludlam HA, Noble WC, Marples RR, Bayston R, Phillips I. The epidemiology of peritonitis caused by coagulasenegative staphylococci in continuous ambulatory peritoneal dialysis. J Med Microbiol 1989; 30: 167-174.

4. Mickelsen PA, Plorde JJ, Gordon KP et al. Instability of antibiotic resistance in a strain of Staphylococcus epidermidis isolated from an outbreak of prosthetic valve endocarditis. J Infect Dis 1985; 152: 50-58.

5. Etienne J, Renaud F, Bes $M$ et al. Instability of characteristics amongst coagulase-negative staphylococci causing endocarditis. J Med Microbiol 1990; 32: 115-122.

6. Clink L, Pennington TH. Staphylococcal whole-cell polypeptide analysis : evaluation as a taxonomic and typing tool. $J \mathrm{Med}$ Microbiol 1987; 23: 41-44.

7. Thomson-Carter FM, Pennington TH. Characterisation of methicillin-resistant isolates of Staphylococcus aureus by analysis of whole-cell and exported proteins. $J$ Med Microbiol 1989; 28: 25-32.

8. Gaston MA, Duff PS, Naidoo J et al. Evaluation of electrophoretic methods for typing methicillin-resistant Staphylococcus aureus. J Med Microbiol 1988; 26: 189-197.

9. Stephenson JR, Tabaqchali S. New method for typing coagulase-negative staphylococci. J Clin Pathol 1986; 39: $127 \mathrm{I}-1275$.

10. Burnie JP, Lee W, Matthews RC, Bayston R. Immunoblot fingerprinting of coagulase-negative staphylococci. $\mathrm{J} \mathrm{Clin}$ Pathol 1988; 41: 103-107.

11. Kersters $\mathrm{K}$, de Ley J. Identification and grouping of bacteria by numerical analysis of their electrophoretic protein patterns. $J$ Gen Microbiol 1975; 87: 333-342.

12. Costas M, Cookson BD, Talsania HG, Owen RJ. Numerical analysis of electrophoretic protein patterns of methicillinresistant strains of Staphylococcus aureus. J Clin Microbiol 1989; 27 : 2574-2581.

13. Cunningham MJ, Noble WC. SDS-PAGE protein patterns of yeasts from human sources. Mycoses 1989; 32: 344-348.

14. Ludlam HA, Nwachukwu B, Noble WC, Swan AV, Phillips I The preservation of micro-organisms in biological specimens stored at $-70^{\circ} \mathrm{C} . J$ Appl Bacteriol 1989; 67: 417-423.

15. Brown D, Blowers R. Disc methods of sensitivity testing and other semiquantitative methods. In: Reeves DS, Phillips I, Williams JD, Wise R (eds) Laboratory methods in antimicrobial chemotherapy. Edinburgh, Churchill Livingstone. 1978; 8-30.

16. Dean BA, Williams REO, Hall F, Corse J. Phage typing of
Whereas the use of antibiogram and biotype profiles is the only practical first-line method for distinguishing isolates of CNS in the routine laboratory, epidemiological investigations demand an effective supplementary method. Plasmid analysis is simple to perform but some isolates are untypable by this method. Wholecell protein typing is discriminatory and permits all isolates to be typed, but demanding techniques such as SDS-PAGE or immunoblotting are unlikely to find use in routine laboratory practice and should be reserved for specific epidemiological problems.

coagulase-negative staphylococci and microcococci. $J \mathrm{Hyg}$ 1973; 71 : 261-270.

17. de Saxe MJ, Crees-Morris JA, Marples RR, Richardson JF Evaluation of current phage-typing systems for coagulasenegative staphylococci. Zentralbl Bakteriol Mikrobiol 1981; Suppl 10: 197-204

18. Richardson JF, Chittasobhon N, Marples RR. Supplementary phages for the investigation of strains of methicillinresistant Staphylococcus aureus. J Med Microbiol 1988; 25 . $67-74$

19, Degener JE, Naidoo JL, Noble WC, Phillips I, Marples RR. Carriage of gentamicin-resistant coagulase-negative staphylococci in patients on continuous ambulatory peritoneal dialysis. J Antimicrob Chemother 1987; 19 505-512.

20. Hancock IC, Poxton IR. Bacterial cell surface techniques. Chichester, John Wiley and Sons Ltd. 1988: 191-192.

21. Jackman PJH. Classification of Corynebacterium species from axillary skin by numerical analysis of electrophoretic protein patterns. J Med Microbiol 1982; 15: 485-492.

22. Sneath PHA, Sokal RR. Numerical taxonomy: the principles and practice of numerical classification. San Francisco, WH Freeman. 1973.

23. Marples RR. Laboratory assessment in the epidemiology of infections caused by coagulase-negative staphylococci. $J$ Med Microbiol 1986; 22: 285-295.

24. Martín-de-Nicolás MM, Vindel A, Sáez-Nieto JA. Development of a new set of phages as an epidemiological marker in Staphylococcus epidermidis causing nosocomial infections. Epidemiol Infect 1990; 104: 111-118.

25. Barzilai A, Hyatt AC, Hodes DS. Demonstration of differences between strains of Staphylococcus aureus by peptidoglycan fingerprinting. $J$ Infect Dis 1984; 150: 583-588.

26. Coia JE, Thompson-Carter F, Baird D, Platt DJ. Characterisation of methicillin-resistant Staphylococcus aureus by biotyping, immunoblotting and restriction enzyme fragmentation patterns. J Med Microbiol 1990; 31 125-132.

27. Pierre J, Gutmann L, Bornet M, Bergogne-Berezin $E$ Williamson $\mathrm{R}$. Identification of coagulase-negative staphylococci by electrophoretic profile of total proteins and analysis of penicillin-binding proteins. $J$ Clin Microbiol 1990; 28 : 443-446.

28. Thomson-Carter FM, Carter PE, Pennington TH. Differentiation of staphylococcal species and strains by ribosomal RNA gene restriction patterns. J Gen Microbiol 1989; 135 : 2093-2097.

29. Freeman R, Gould FK, Wilkinson R, Ward AC, Lightfoot NF, Sisson PR. Rapid inter-strain comparison by pyrolysis mass spectrometry of coagulase-negative staphylococci from persistent CAPD peritonitis. Epidemiol Infect 1991 106: $239-246$. 